\title{
Polyunsaturated fatty acids and diabetic retinopathy
}

\author{
JULIA HOWARD-WILLIAMS,' P PATEL, ${ }^{2} R$ JELFS, ${ }^{2} R$ D CARTER, ${ }^{2} P$ AWDRY,' \\ A BRON,' J I MANN,' AND T D R HOCKADAY'
}

From the 'Oxford Eye Hospital, Oxford, and the ${ }^{2}$ Radcliffe Infirmary, Oxford

SUMMARY One hundred and forty nine diabetic patients were ophthalmologically assessed seven years after randomisation to a low carbohydrate or modified fat diet (rich in linoleic acid). Glycaemic control, regardless of the type of diet, was a major determinant of the development of retinopathy. Poorly controlled patients (haemoglobin A1c $>8 \%$ ) with low levels of linoleic acid in cholesterol ester had a significantly greater frequency of retinopathy than well controlled patients or patients with similarly unsatisfactory control but higher levels of linoleic acid. The findings support an earlier suggestion that linoleic acid might protect against diabetic retinopathy.

Most diabetic patients in western countries have until recently been advised to follow a low carbohydrate diet. Such diets are invariably relatively high in fat, but little attention has been paid to the type of fat eaten. ${ }^{\prime}$ Evidence of the beneficial effect of dietary fibre on glycaemic control has led to a change in diabetic dietary policy in several countries. Diabetics are now advised that at least half their daily energy intake should come from fibre rich complex carbohydrates. ${ }^{2}$ There is still no firm recommendation concerning the optimal sources of fat, and most diabetics derive the bulk of their fat calories from saturated animal fat.

There are several reasons why diabetics might benefit if an appreciable proportion of dietary fat is polyunsaturated. Polyunsaturated fatty acids (PUFA) have a cholesterol lowering effect which might reduce the risk of cardiovascular disease, which is particularly high among diabetics. ${ }^{3}$ In addition PUFA apparently have some antithrombotic effect (and in particular an action reducing platelet aggregation) at least partly because they are precursors of certain prostaglandins. ${ }^{45}$ Finally, Houtsmuller et al..$^{6}$ have suggested that in non-insulin dependent diabetics a diet rich in PUFA taken for three to six years might delay the development and progression of retinopathy during that time. A study in which maturity onset diabetics were randomised between two types of dietary advice varying in PUFA intake provides a test for the hypothesis of Houtsmuller $e t$ al.

Correspondence to Dr J I Mann, Radcliffe Infirmary, Oxford OX2 6HE.

\section{Material and methods}

Patients. In 1973 a prospective study of newly diagnosed maturity onset diabetics referred to the Radcliffe Infirmary Diabetic Clinic was started. Between 1973 and 1976250 patients were recruited and then randomised to advice on either a standard low carbohydrate diet (LC) or a diet with a modified fat intake (MF), the details of which are given below. To be considered for entry patients had to be less than 66 years old and untreated except, in some cases, for some general dietary advice from their general practitioners. Excluded were patients on any treatment that would grossly disturb carbohydrate metabolism, who had an imminently life threatening condition, or who were reckoned clinically to require insulin treatment immediately. The presence (or past history) of any other endocrine disease, angina pectoris, or neurological deficit following a cerebrovascular accident precluded admission, as did the presence, but not a past history, of liver disease.

All the patients in the original study were invited to the Oxford Eye Hospital for a review of ophthalmological findings in 1982. One hundred and fifty of the original cohort of 250 attended. Of the remaining 100,22 had died, 20 had moved or emigrated, and 58 declined the invitation to attend for ophthalmological review. One attender had cataracts preventing funduscopy and photography and was therefore excluded from all analyses. The ophthalmological features of the 100 non-attenders differed at entry to the trial from the patients who agreed to be reexamined. In addition those examined were older, 
Table 1 Comparison of features before treatment and known liability to retinopathy of those attending and not attending ophthalmological review in 1982

\begin{tabular}{|c|c|c|c|}
\hline & $\begin{array}{l}\text { Reviewed } \\
(n=149)\end{array}$ & $\begin{array}{l}\text { Not reviewed } \\
(n=I 00)\end{array}$ & $p$ \\
\hline Age (ycars) & $57 \cdot 8 \pm(0 \cdot 8$ & $48 \cdot 7 \pm 1 \cdot 2$ & $(0 \cdot()(0) 1$ \\
\hline Sex, $\%$ male & 55 & 41 & NS \\
\hline Body mass index (BMI) & $27 \cdot 7 \pm(0 \cdot 5$ & $29 \cdot 8 \pm 0 \cdot 5$ & ()$\cdot(02$ \\
\hline $\begin{array}{l}\text { History of symptoms before } \\
\text { entry (months) }\end{array}$ & $4 \cdot 3 \pm 1 \cdot 2$ & $8 \cdot 6 \pm 1 \cdot 6$ & 0.05 \\
\hline Fasting glucosc $(\mathrm{mmol} / \mathrm{l})$ & $11 \cdot 8 \pm 0.33$ & $11 \cdot 4 \pm 0 \cdot 4$ & NS \\
\hline $\begin{array}{l}\text { Number with retinopathy at } \\
\text { diagnosis }\end{array}$ & 3 & 14 & \\
\hline $\begin{array}{l}\text { Number without retinopathy } \\
\text { at diagnosis }\end{array}$ & 136 & 46 & \\
\hline $\begin{array}{l}\text { Number without full ocular } \\
\text { examination at diagnosis }\end{array}$ & 10 & 4() & \\
\hline
\end{tabular}

NS = not significant at $5 \% \mathrm{lcvel}$.

less obese, and had a shorter history of symptoms at diagnosis than those not examined seven years later (Table 1). However, the two groups did not then differ significantly as to sex or in fasting blood glucose. Of the 149 patients $78(52 \%)$ were initially assigned to LC and $71(48 \%)$ to MF. The diet groups were well matched for age, sex, and body mass index.

Dietary advice. At diagnosis the patients were advised to follow either a classical low carbohydrate diabetic diet or a relatively high carbohydrate, modified fat diet. ${ }^{7}$ The advised energy intake was determined according to percentage above ideal body weight. In LC the advice was to restrict carbohydrate to a maximum of $40 \%$ of total energy. Protein provided up to $20 \%$ and fat about $40 \%$ total energy with a ratio of PUFA to saturated fatty acids (P:S) about $0 \cdot 3$. MF was originally designed to be a lipid lowering diet. It was therefore advised that fats should provide no more than $30 \%$ total energy (with a P:S ratio of 0.9 or above). Protein once again provided about $20 \%$ and carbohydrate in this diet about $50 \%$ of total energy. Cholesterol was restricted to a maximum of $2 \cdot 1$ g weekly.

On review in 1982 each patient was interviewed by a dietitian who took a full dietary history with particular reference to the amount and type of fat and carbohydrate. On the basis of the dietary interview and their known randomisation, but without knowledge of any clinical data, she divided the patients according to whether she believed them to be complying faithfully with the principles of the dietary advice (compliers) or not (non-compliers). Thirty nine of the $79(49 \%)$ allocated to LC and 19 out of the $70(27 \%)$ allocated to MF were considered to be compliers. At this assessment initial dietary advice was reinforced, as it had been intermittently at outpatient visits since diagnosis.
Ophthalmological assessment. At the time of diagnosis all patients were assessed by a consultant ophthalmologist (P.A.). The ophthalmological assessment included visual acuity and ophthalmoscopic examination of the fundus. In patients with retinopathy each feature of the retinopathy (that is, exudate, microaneurysm, haemorrhage, and new vessels) was compared with the Hammersmith series of colour photographs grade B and noted to be either absent or less than, the same as, or more than standard photo B. At the 1982 assessment the patient's fundi were also photographed with a Zeiss fundus camera and Ektachrome 64 film. Eight $30^{\circ}$ views were taken to include disc, macula, nasal to disc, and temporal to macula, and four diagonal views about the disc. In patients with background retinopathy this was quantified in detail by creating a montage of the fundus with a back projection system, in which each microaneurysm, new vessel, cotton wool spot, exudate, and haemorrhage was colour coded and drawn on an acetate sheet. The numbers of microaneurysms, cotton wool spots, and new vessels were counted and the areas of exudate and haemorrhage measured by computer planimetry. A retinopathy index ${ }^{x}$ was devised by adding the scores for each feature and then calculating a weighted index. Even one microaneurysm on the fundus photograph resulted in a positive classification for retinopathy.

Metabolic assessment. A detailed metabolic assessment was made initially and at one, three, and five years after diagnosis. The data presented here relate to selected measurements at these times as well as to the time of the 1982 ophthalmological assessment when, in addition, a random blood sample was taken for measurement of blood glucose, haemoglobin A1c, total cholesterol, and cholesterol in the various lipoprotein fractions, and fatty acid composition of the cholesterol esters." " Cholesterol ester rather than triglyceride fatty acids were studied, since (unlike the triglycerides) this fraction is uninfluenced by the fact that fasting samples were not available. Haemoglobin Alc, total and subfraction cholesterols are similarly little influenced by diurnal variation. Triglycerides were not measured because of the marked difference when studied in the non-fasting state.

\section{Results}

No MF complier had retinopathy at diagnosis. Thirty eight of the 39 compliant patients on LC had been recorded free of retinopathy at diagnosis, but no fundal assessment was recorded then for the other one. In the 1982 review this patient had only one microaneurysm. At the seven-year ophthalmological 
Table 2 Frequency of retinopathy among compliers and non-compliers according to dietary advice

\begin{tabular}{|c|c|c|c|c|c|c|}
\hline & \multicolumn{3}{|c|}{ Low carbohydrate } & \multicolumn{3}{|l|}{ Modified fat } \\
\hline & No retinopathy & Retinopathy & Total & No retinopathy & Retinopathy & Total \\
\hline Complicrs & $23(59 \%)$ & $16(41 \%)$ & 39 & $15(79 \%)$ & $4(21 \%)$ & 19 \\
\hline Non-complicrs & $28(70 \%)$ & $12(30 \%)$ & 40 & $28(55 \%)$ & $23(45 \%)$ & 51 \\
\hline Total & $51(65 \%)$ & $28(35 \%)$ & 79 & $43(61 \%)$ & $27(39 \%)$ & 70 \\
\hline
\end{tabular}

Table 3 Fatty acid composition of the cholesterol esters in patients on LC and MF (mean \% of total $\pm S D$ )

\begin{tabular}{|c|c|c|c|c|c|c|}
\hline & \multicolumn{3}{|c|}{ All patients } & \multicolumn{3}{|c|}{ Compliers } \\
\hline & $L C$ & $M F$ & $p$ & $L C$ & $M F$ & $p$ \\
\hline C16:() & $9 \pm 2 \cdot 8$ & $8 \pm 2 \cdot 1$ & NS & $9 \pm 3 \cdot 3$ & $7 \pm 1 \cdot 6$ & $0 \cdot 051$ \\
\hline C16:1 & $6 \pm 3 \cdot 2$ & $5 \pm 2 \cdot 3$ & $0 .(045$ & $5 \pm 2 \cdot 4$ & $4 \pm 1 \cdot 7$ & $0 \cdot 037$ \\
\hline C18:() & $1 \pm 2 \cdot 5$ & $1 \pm 2.7$ & NS & $1 \pm 2 \cdot 7$ & $1 \pm 2 \cdot 2$ & NS \\
\hline C18:1 & $16 \pm 4 \cdot()$ & $13 \pm 3 \cdot 7$ & 0.0012 & $15 \pm 3 \cdot 3$ & $11 \pm 2 \cdot 5$ & 0.001 \\
\hline C18:2 & $40 \pm 8 \cdot 6$ & $46 \pm 8 \cdot 4$ & 0.001 & $39 \pm 9 \cdot 3$ & $45 \pm 10 \cdot 2$ & $0 \cdot(043$ \\
\hline C18:3 & $0.5 \pm 2 \cdot 6$ & $0.5 \pm 2.7$ & NS & $0.5 \pm 2.6$ & $0.5 \pm 2.2$ & NS \\
\hline C2(): 4 & $6 \pm 3 \cdot 7$ & $6 \pm 2 \cdot 8$ & NS & $6 \pm 3 \cdot 7$ & $6 \pm 2 \cdot()$ & NS \\
\hline
\end{tabular}

assessment those patients complying with MF tended to have retinopathy less often than LC compliers $(21 \%$ versus $41 \%)$ or the non-compliers, but this difference was not statistically significant $\left(\chi^{2}=2 \cdot 25\right.$, Table 2).

Diabetic control. No significant difference between LC and MF was found in glycaemic control as measured either by the mean fasting glucose one, three, and five years after diagnosis, or $\mathrm{HbAlc}$, or random glucose at ophthalmological review. Dividing the patients into compliers and noncompliers still did not identify any difference between the diet groups in these factors. More notably, when all 149 patients were considered together, the presence of retinopathy correlated with the fasting glucose level at diagnosis, the mean of values of fasting glucose at one, three, and five years, and also with random glucose and haemoglobin Alc levels measured at the 1982 review. (These results are presented in detail elsewhere." )

Treatment. Patients entered into the study did not require insulin initially, but subsequently $22(15 \%)$ have been started on insulin and $73(49 \%)$ patients on oral hypoglycaemic agents, so $55(37 \%)$ have con-

Table $4 \%$ of linoleic acid in cholesterol esters in various groups of patients

\begin{tabular}{lll}
\hline & Retinopathy & No retinopathy \\
\hline Modified fat dict (all patients) & $45 \pm 7(24)$ & $46 \pm 9(37)$ \\
Modificd fat dict (complicrs) & $42 \pm 8(5)$ & $46 \pm 11(13)$ \\
Low carbohydratc dict (all paticnts) & $39 \pm 9(22)$ & $40 \pm 9(49)$ \\
Low carbohydrate dict (complicrs) & $38 \pm 9(15)$ & $39 \pm 10(19)$ \\
\hline
\end{tabular}

tinued on diet alone. The frequency of retinopathy was higher in the insulin and tablet treated patients ( $45 \%$ and $46 \%$ respectively) than in those continuing on diet alone $(22 \%)$. This difference could be related to higher blood glucose levels in the insulin and tablet treated groups.

Lipid results. Patients advised to follow MF had significantly lower levels of total cholesterol over the five years of follow-up than LC (cholesterol mean \pm SD at years 13 , and $5: 187 \pm 35 \mathrm{mg} / \mathrm{dl}$ on $\mathrm{MF}$ and $211 \pm 37 \mathrm{mg} / \mathrm{dl}$ on LC, $\mathrm{p}<0 \cdot 001)$ (SI: $4 \cdot 8 \pm 0.91 \mathrm{mmol} / \mathrm{l}$ on MF and $5.5 \pm 0.96 \mathrm{mmol} / \mathrm{l}$ on LC). At the time of diagnosis cholesterol levels in the two groups were identical. The fatty acid composition of the plasma cholesterol esters measured at the ophthalmological review also differed appreciably on the two diets (Table 3). Levels of linoleic acid were higher on MF than LC, but levels of myristic and oleic acid were higher on LC. Patients with retinopathy tended to have a lower percentage of linoleic acid in cholesterol esters than those without retinopathy, but there were no significant differences in fatty acid composition of cholesterol ester between these two groups of patients (Table 4).

Houtsmuller et al. " found virtually no retinopathy among their diabetics whose percentage of linoleic acid in cholesterol esters exceeded $50 \%$. Their patients were all described as 'poorly controlled.' In our patients glycaemic control is a major determinant of retinopathy. We therefore divided patients according to both glycosylated haemoglobin and percentage of cholesterol esters as linoleate (Table 5 ). Poorly controlled patients (HbA1c $>8 \%$, our upper limit of normal) with cholesterol ester linoleate 
Table 5 Frequency of retinopathy according to haemoglobin AIc and \% of linoleic acid in cholesterol ester

\begin{tabular}{|c|c|c|c|c|}
\hline & \multicolumn{2}{|c|}{ Haemoglobin Alc $>8 \%$} & \multicolumn{2}{|c|}{ Haemoglobin Alc $>8 \%$} \\
\hline & Retinopathy & No retinopathy & Retinopathy & No retinopathy \\
\hline Cholesterol ester C $18: 2>50 \%$ & $6(37 \%)$ & $10(63 \%)$ & $3(20 \%)$ & $12(80 \%)$ \\
\hline Cholesterol ester C $18: 2<50 \%$ & $24(53 \%)$ & $21(47 \%)$ & $10(21 \%)$ & $37(79 \%)$ \\
\hline Total & $30(49 \%)$ & $31(51 \%)$ & $13(21 \%)$ & $49(79 \%)$ \\
\hline
\end{tabular}

$<50 \%$ had a significantly greater frequency of retinopathy than the remaining patients $\left(\chi^{2}=10 \cdot 5\right.$, $\mathrm{p}<0 \cdot 005)$. In patients with relatively good glycaemic control (HbAlc $<8 \%$ ) levels of linoleic acid appear not to influence the frequency of retinopathy. A similar trend is seen if, rather than haemoglobin Alc, fasting blood glucose at one, three, and five years is used to distinguish well controlled from poorly controlled patients.

\section{Discussion}

In 1979 Houtsmuller and colleagues described a dramatic reduction in the development of retinopathy among diabetic patients with poor glycaemic control who ate diets high in polyunsaturated fatty acids. Over a six-year period they found that $92 \%$ of patients on a diet low in linoleic acid showed the development or progression of retinopathy. Among those on a diet rich in PUFA minimal progression of retinopathy was reported. ${ }^{6}$

Despite the fact that a proportion of the original cohort could not be followed up, our data provide some confirmation that linoleic acid protects against the development of retinopathy, but the results are not as striking as the earlier report, possibly for two reasons. First, our patients did not show as high a level of linoleic acid in the cholesterol esters, probably because they ingested less linoleate than the Dutch. It may be that a higher proportion of linoleate is necessary for demonstrable benefit. Second, blood glucose control is a major determinant of retinopathy," and the effect of linoleic acid may be less marked with tighter rather than with looser glycaemic control. The precise relationship between the effects of glycaemia and linoleic acid on retinopathy is likely to be complex and may require a study of larger numbers of patients to disentangle separate effects.

At the time of ophthalmological reassessment all our patients were given dietary reinforcement. We hope thus to increase linoleic acid levels in patients recommended $\mathrm{MF}$ and so test more adequately whether linoleic acid indeed protects against retinopathy during the next two years of follow-up.

We are grateful to Miss $\mathrm{R}$ Longstaff, Mr R Howarth, and Miss $\mathrm{E}$ Todd, who assisted initially with the dictary aspects of the study, and to the Simon Broome Heart Research Trust, the British Diabetic Association, and the Oxford Diabetes Trust for financial support. Plasma glucose concentrations were analysed at the intervening metabolic clinical reviews in the Department of Clinical Biochemistry, John Radeliffe Hospital under the supervision of Dr R Wilkinson, and we are very grateful to him for these results. We are very grateful to Mrs Anne Reeve for preparing the manuscript and to Miss V Beckett of the Sheikh Rashid Diabetes Unit for skilled statistical advice.

\section{References}

1 Mann JI. Diet and diabetes. Diabetologia 1980); 18: 89-95.

2 Nutrition Subcommittec of the British Diabetic Association's Medical Advisory Committee. Dietary recommendations for the 1980) - a policy statement by the British Diabetic Association. Human Nutrition: Applied Nutrition 1982; 36A: 378-86.

3 Jarrett RJ. Diabetes and the heart: coronary heart disease. $J$ Endocrinol (Oxf) 1977; 6: 389-4(12.

4 Renaud S, Morazain R, Godsey F. Platelet functions in relation to dict and serum lipids in British farmers. Br Heart J 1981; 46: $562-70$.

5 Gerrard JM. White JG. Labile aggregation stimulating substance, free fatty acids and platelet aggregation. J Lab Clin Med 1976; 87: 73-82.

6 Houtsmuller AJ, Zahn KJ, Henkes HE. Unsaturated fats and progression of diabetic retinopathy. Doc Ophthalmol 1979;48: $363-71$.

7 Hockaday TDR, Hockaday JM, Mann JI, Turner RC. A prospective comparison of modificd fat-high carbohydrate with standard low-carbohydrate dietary advice in the treatment of diabetes: a one year follow-up study. BrJ Nutr 1978; 39: 357-62.

8 Holman RR. Dornan TL. Mayon-White R. Prevention of deterioration of renal and sensory-nerve function by more intensive management of insulin-dependent diabetic patients Lancet 1983; i: 204-8.

9 Jones DB, Carter RD, Haitas B, Mann JI. Low phospholipid arachidonic acid levels in diabetic platelets. $B r$ Med J 1983; 286: $173-5$.

10 Moore RA. Oppert S. Eaton P. Mann JI. Triglyceride fatty acids confirm a change in dictary fat. Clin Endocrinol (Oxf) 1977; 7: $143-9$.

11 Howard-Williams J, Hillson RM, Bron A, Awdry P. Mann JI. Hockaday TDR. Retinopathy is associated with higher glycaemia in maturity-type onset diabetes. Diabetologia 1984; 27: 198-202. 